This item was submitted to Loughborough's Research Repository by the author.

Items in Figshare are protected by copyright, with all rights reserved, unless otherwise indicated.

\title{
Staphylococcus aureus resists UVA at low irradiance but succumbs in the presence of $\mathrm{TiO} 2$ photocatalytic coatings
}

PLEASE CITE THE PUBLISHED VERSION

https://doi.org/10.1016/j.jphotobiol.2019.02.009

\section{PUBLISHER}

(C) Elsevier

\section{VERSION}

AM (Accepted Manuscript)

\section{PUBLISHER STATEMENT}

This paper was accepted for publication in the journal Journal of Photochemistry and Photobiology B: Biology and the definitive published version is available at https://doi.org/10.1016/j.jphotobiol.2019.02.009.

\section{LICENCE}

CC BY-NC-ND 4.0

\section{REPOSITORY RECORD}

Clemente, Andrea, J.J. Ramsden, Alec Wright, Felipe Iza, Julie A. Morrissey, Gianluca Li-Puma, and Danish Malik. 2019. "Staphylococcus Aureus Resists UVA at Low Irradiance but Succumbs in the Presence of Tio2 Photocatalytic Coatings". figshare. https://hdl.handle.net/2134/37187. 
1 Staphylococcus aureus resists UVA at low irradiance but succumbs in the

2 presence of $\mathrm{TiO}_{2}$ photocatalytic coatings

3 Andrea Clemente ${ }^{1}$, Jeremy J. Ramsden ${ }^{2}$, Alec Wright $^{3}$, Felipe Iza $^{3}$, Julie A. Morrissey ${ }^{4}$,

4 Gianluca Li Puma ${ }^{1}$ and Danish J. Malik ${ }^{1 *}$

$5{ }^{1}$ Department of Chemical Engineering, Loughborough University, Loughborough,

6 United Kingdom

$7 \quad 2$ Clore Laboratory, University of Buckingham, Buckingham, United Kingdom.

83 Wolfson School of Mechanical, Electrical and Manufacturing Engineering,

9 Loughborough University, Loughborough, United Kingdom

104 Department of Genetics, University of Leicester, Leicester, United Kingdom

$11 *$ Corresponding author

12 Email: d.j.malik@lboro.ac.uk (Correspondence and reprints)

13 ABSTRACT

14 The aim of this study was to evaluate the bactericidal effect of reactive oxygen

15 species (ROS) generated upon irradiation of photocatalytic $\mathrm{TiO}_{2}$ surface coatings

16 using low levels of UVA and the consequent killing of Staphylococcus aureus. The

17 role of intracellular enzymes catalase and superoxide dismutase in protecting the bacteria was investigated using mutant strains. Differences were observed in the intracellular oxidative stress response and viability of $S$. aureus upon exposure to UVA; these were found to be dependent on the level of irradiance and not the total

21 UVA dose. The wild type bacteria were able to survive almost indefinitely in the 22 absence of the coatings at low UVA irradiance ( $\left.\mathrm{LI}, 1 \mathrm{~mW} / \mathrm{cm}^{2}\right)$, whereas in the 
23 presence of $\mathrm{TiO}_{2}$ coatings, no viable bacteria were measurable after 24 hours of exposure. At $\mathrm{LI}$, the lethality of the photocatalytic effect due to the $\mathrm{TiO}_{2}$ surface coatings was correlated with high intracellular oxidative stress levels. The wild type strain was found to be more resistant to UVA at $\mathrm{HI}$ compared with an identical dose at $\mathrm{LI}$ in the presence of the $\mathrm{TiO}_{2}$ coatings. The UVA-irradiated titania operates by a "stealth" mechanism at low UVA irradiance, generating low levels of extracellular lethal ROS against which the bacteria are defenceless because the low light level fails to induce the oxidative stress defence mechanism of the bacteria. These results are encouraging for the deployment of antibacterial titania surface coatings wherever it is desirable to reduce the environmental bacterial burden under typical indoor 33 lighting conditions.

34 Keywords: UVA, photocatalysis, reactive oxygen species, Staphylococcus aureus, 35 titanium dioxide

\section{Introduction}

37 Surfaces in many industries, including healthcare, hospitality and leisure services, require regular cleaning and disinfection to maintain environmental hygiene and prevention of cross-transmission of pathogenic bacteria (Dancer, 2008). Conventional methods of cleaning and disinfection with wiping are not particularly

41 effective, whilst also being time- and resource-intensive (White et al., 2008). Surface recontamination rates following cleaning are rapid (Hardy et al., 2007). Other methods of environmental surface decontamination include use of steam, hydrogen

44 peroxide vapour, ozone and UV light (Khan et al., 2012). However, the effectiveness of these methods is limited because uniform dispersal of the active agent in a 3dimensional space is rarely achieved. 
47 A recent study evaluated the use of photocatalytic surface coatings to reduce the bioburden of frequently touched surfaces in a healthcare environment and reported a lower microbial burden on surfaces treated with a commercial $\mathrm{TiO}_{2}$-based photocatalytic coating (Reid et al., 2018). The efficacy of irradiated titania $\left(\mathrm{TiO}_{2}\right)$ as an antibacterial agent has long been known (Matsunaga et al., 1985). There have been many laboratory experiments corroborating this photocatalytic effect against both Gram-negative bacteria (e.g., Escherichia coli and Pseudomonas aeruginosa) and Gram-positive bacteria like Staphylococcus aureus (Kühn et al., 2003; Nakano et al., 2013; Sunada et al., 2003).

$\mathrm{TiO}_{2}$ exists in three crystallographic phases: anatase, brookite and rutile. Their band gaps, mechanisms of light absorption and photocatalytic activities differ (Zhang et al., 2014). All the band gaps are in the violet-ultraviolet region; in actual samples surface and impurity states may shift the absorption to longer wavelengths (Ramsden, 2015). However, most experimental studies use near-ultraviolet light (typically UVA, 320-380 nm) to investigate the photocatalytic antimicrobial action. It is now known that such light itself has some antimicrobial action (Merwald et al., 2005). Shorter-wavelength ultraviolet light (UVC) is already well-established as an antimicrobial agent in healthcare facilities (Rastogi, 2007). However, UVC is harmful to human beings, whereas mild UVA can be used in their presence, hence is more amenable for use in hospitals and in hospitality and catering industries such as food preparation areas to promote continuous disinfection and environmental hygiene. Band-gap irradiation of $\mathrm{TiO}_{2}$ produces highly reactive oxygen species (ROS), especially superoxide, hydroxyl and perhydroxyl radicals (Hirakawa and Nosaka, 2002; Kikuchi et al., 1997; Ramsden, 2015). There is realization that bacteria may not be able to develop resistance to all of the different ROS species 
72 photocatalytically generated (Ramsden, 2017). This has raised interest in

73 photocatalytic antimicrobial materials, especially because of the global health threat

74 posed by the increasingly prevalent antimicrobial resistance (O’Neill, 2016).

75 S. aureus was chosen in the present study as an example of a typical problematic 76 pathogen. It is a Gram-positive bacterium of interest to hospital hygienists, because

77 of the widespread prevalence of methicillin-resistant $S$. aureus strains (MRSA),

78 which are associated with healthcare-associated infections, increased lengths of stay

79 in hospitals, increased healthcare costs and increased mortality (Goodman et al.,

80 2008). Surfaces in rooms occupied by MRSA-positive patients can contaminate the

81 hands of healthcare workers and result in cross-transmission. Studies have

82 demonstrated that these organisms can survive and persist in the environment for

83 prolonged periods despite routine cleaning (Kramer et al., 2006).

84 In the present study, viability of wild type S. aureus $\mathrm{SH} 1000$ and isogenic mutants 85 defective in either peroxide or superoxide detoxification on P25 titanium dioxide $86\left(\mathrm{TiO}_{2}\right)$ films at low and high UVA irradiances was investigated to elucidate the 87 mechanisms of bactericidal activity. At low natural irradiance (representative of 88 indoor lighting conditions) UVA has very low, if any, bactericidal action; however, at 89 high irradiance, bactericidal action has been noted (Kramer and Ames, 1987). The 90 effect of photocatalytically induced reactive oxygen species on intracellular oxidative 91 stress in bacteria was investigated and their bactericidal effect was quantified. 


\section{Chemical reagents}

$95 \mathrm{P}_{25} \mathrm{TiO}_{2}$ was purchased from Evonik Industries AG, Germany. Terephthalic acid

96 (TPA), hydroxyterephthalic acid (hTPA), indigo trisulfonate (ITS), 2,7-

97 dichlorofluorescein diacetate (DCFH-DA) and 2,7-dichlorofluorescein (DCF), ethanol

98 (99.8+\% analytical grade), phosphoric acid (99.9+\% analytical grade), sodium phosphate monobasic (reagent grade) were purchased from Sigma Aldrich (UK).

\section{Photocatalysis reactor experimental set-up}

101 The photocatalytic experiments were carried out in a specially designed and built

102 photoreactor (Fig. 1). It consists of two identical rectangular boxes equipped with a

103 lid that can be unfastened to allow ease of access to Petri dishes ( 4 per box). The 104 photoreactor was equipped with a black-light UV-A fluorescent lamp (tubular $\sim 50 \mathrm{~cm}$ length, $26 \mathrm{~mm}$ diameter, Philips 8W/BLB, wavelength $(\lambda) 360 \mathrm{~nm}$ ) positioned $\sim 4 \mathrm{~cm}$

106 above the Petri dish in the centre of each box. Inside the irradiation compartment,

107 local measurements of the irradiance were made using a radiometer (ILT 1700, International Light Technologies) equipped with a SED 033 sensor calibrated with appropriate filters. The spatial distribution of light intensity across the four Petri dishes was found to be uniform within measurement error ( $\pm 2 \%$ of irradiance). The

111 boxes were placed on a platform rocker (Stuart Scientific, UK, 3D Rocking platform,

112 Model STR9) with a frequency of 5 rev $\mathrm{min}^{-1}$. The Petri dishes containing the glass

113 slides (with and without $\mathrm{TiO}_{2}$ coating) contained $15 \mathrm{ml}$ of sterile deionized water. The

114 liquid depth in the Petri dishes was $\sim 2 \mathrm{~mm}$. Samples were exposed at a controlled 115 irradiance of $1.00 \pm 0.05 \mathrm{~mW} \mathrm{~cm}^{-2}$ (low irradiance, LI) and $4.00 \pm 0.05 \mathrm{~mW} \mathrm{~cm}^{-2}$ (high 116 irradiance, $\mathrm{HI})$. 


\section{Fabrication of $\mathrm{TiO}_{2}$ films}

$118 \mathrm{TiO}_{2}$ nanoparticles were suspended in ethanol at a concentration of $25 \mathrm{~g} \mathrm{I}^{-1}$.

119 Borosilicate glass microscope slides (Sigma Aldrich, UK, $38 \mathrm{~mm} \times 75 \mathrm{~mm}$ ) were

120 washed with ethanol under sonication and subsequently air-dried in a laminar flow

121 hood. The slides were then coated with $\mathrm{TiO}_{2}$ using a standard dip-coating procedure

122 (Fig. 1): they were rigidly clamped to a motorised rod that allowed a dipping and

123 withdrawal rate of $3 \mathrm{~cm} \mathrm{~min}^{-1}$. Coating was carried out at room temperature $\left(25^{\circ} \mathrm{C}\right)$.

124 The slides were dipped in the $\mathrm{TiO}_{2}$ suspension (100 $\mathrm{ml}$ beaker equipped with a

125 magnetic stirrer to ensure uniform dispersion of $\mathrm{TiO}_{2}$ nanoparticles). The weight gain

126 of the slide after each coating cycle (i.e., dipping and withdrawing) was measured

127 using a six-digit balance (Sartorius, UK). The process was repeated several times

128 until the mass of $\mathrm{TiO}_{2}$ deposited on each slide reached $0.5 \pm 0.05 \mathrm{mg}$. The ethanol

129 was allowed to evaporate at room temperature between each coating cycle (the

130 drying process took $\sim 45 \mathrm{sec})$.

\section{Characterization of $\mathrm{TiO}_{2}$ coatings}

132 The morphology of the $\mathrm{TiO}_{2}$ particles was examined using a field emission gun

133 scanning electron microscope (FEG-SEM), also used for characterization of surface

134 morphology and coating thickness (Leo Elektronenmikroskopie GmbH model 1530

135 VP equipped with an EDAX Pegasus (EBSD/EDXA) unit). Sputter coating (for $60 \mathrm{~s}$ )

136 of the samples prior to SEM imaging was carried out using gold/palladium (Au/Pd)

137 alloy. 
139 Bacterial strains, media and growth conditions

140 The antibacterial photocatalytic coatings were tested against $S$. aureus wild type

$141 \mathrm{SH} 1000$ and isogenic mutants defective in peroxide (SH1000 ahpC/katA) and

142 superoxide (SH1000 sodA/sodM) detoxification (Cosgrove et al., 2007; Karavolos et

143 al., 2003).S. aureus strains were grown in a brain-heart infusion (BHI, Oxoid) culture

144 medium at $37^{\circ} \mathrm{C}$ overnight. An aliquot of the overnight culture was transferred in

145 fresh $\mathrm{BHI}$ broth to reach an optical density (OD) of 0.05 at $600 \mathrm{~nm}$. According to the

146 growth curve of each strain (data not shown), the concentration of bacterial cells was

147 adjusted to a target concentration of $2.5 \times 10^{6} \mathrm{CFU} \mathrm{ml}{ }^{-1}$. The bacteria were

148 centrifuged at $2500 \mathrm{~g}$ for $5 \mathrm{~min}$ at $4^{\circ} \mathrm{C}$ and the pellets of bacterial cells were

149 resuspended in $1 \mathrm{ml}$ of deionized sterile water after removing any growth medium

150 traces. The bacterial suspension was then added to $14 \mathrm{ml}$ deionized sterile water in

151 the Petri dishes before the start of each experiment. Suspension samples were

152 taken at intervals during irradiation and plated after serial dilution on $\mathrm{BHI}+5 \%$ blood

153 agar plates (TCS Biosciences) and incubated at $37^{\circ} \mathrm{C}$ for $24 \mathrm{~h}$, to measure cell

154 viability as colony-forming units $\left(\mathrm{CFU} \mathrm{ml} \mathrm{m}^{-1}\right)$.

\section{Quantification of hydroxyl radicals and hydrogen peroxide}

156 The hydroxyl radical production rate of the coatings was obtained by monitoring the

157 rate of reaction of hydroxyl radicals produced during the photocatalytic process and

158 terephthalic acid (TPA) reagent added to the solution. In alkaline aqueous solution,

159 TPA produces terephthalate anions, these react with hydroxyl radicals to produce

160 highly fluorescent hydroxyl-terephthalate ions (hTPA) (Mason et al., 1994). A

161 solution of $2 \mathrm{mM}$ TPA in phosphate buffer $(\mathrm{pH} 7)$ was made and $15 \mathrm{ml}$ were poured

162 into each Petri dish. The fluorescence of each sample was measured using a Perkin- 
163 Elmer LS-50 luminescence spectrometer with an excitation wavelength of $315 \mathrm{~nm}$ 164 and analysing the emission at $425 \mathrm{~nm}$. A stock solution of $2 \mathrm{mM}$ in phosphate buffer of 2-hydroxyterephthalic acid was prepared for calibration purposes. This is the final product of the chemical reaction between terephthalic acid and the hydroxyl radicals

167 produced during the photocatalytic process. The fluorescent signals of serial

168 dilutions from the stock solution was monitored and used to construct the calibration 169 curve.

170 The aqueous $\mathrm{H}_{2} \mathrm{O}_{2}$ concentration was measured by the standard titanium sulphate 171 colorimetric method (Machala et al., 2013). The reaction results in a yellow-coloured 172 complex according to the following scheme: $\mathrm{Ti}^{4+}+\mathrm{H}_{2} \mathrm{O}_{2}+2 \mathrm{H}_{2} \mathrm{O} \rightarrow \mathrm{H}_{2} \mathrm{TiO}_{4}$

173 (pertitanic acid) $+4 \mathrm{H}^{+}$. The complex is stable for at least $6 \mathrm{~h}$. Absorbance was read 174 at $407 \mathrm{~nm}$ using a UV-Vis spectrophotometer (Shimadzu, UV Mini 1240).

\section{Photocatalytic activity test}

176 The degradation of indigo trisulfonate (ITS) in aqueous solution was monitored to 177 evaluate the photocatalytic activity of the prepared coatings. ITS is a well known 178 redox indicator of oxidative stress. The indigo molecule has only one $\mathrm{C}=\mathrm{C}$ double 179 bond, which is highly reactive with the ROS produced during the photocatalytic 180 process. Oxidative cleavage of the $\mathrm{C}=\mathrm{C}$ bond eliminates the absorbance at $600 \mathrm{~nm}$ 181 (Dorta-Schaeppi and Treadwell, 1949).

182 An ITS stock solution (0.1 mM) was made in deionized water. A fresh test solution 183 was prepared by mixing $5 \mathrm{~g}$ sodium phosphate monobasic, $3.5 \mathrm{ml}$ concentrated 184 phosphoric acid, $20 \mathrm{ml}$ ITS stock solution and pure water up to final volume of 500 $185 \mathrm{ml}$. The $\mathrm{pH}$ of the resulting test solution was 3.0. During irradiation $0.5 \mathrm{ml}$ of indigo 
186

187

188

189

190

191

192

193

194

195

196

197

198

199

200

201

202

203

204

205

206

207

solution was taken every hour and the indigo concentration was determined spectrophotometrically at $605 \mathrm{~nm}$.

\section{Quantification of total intracellular ROS concentration}

Quantification of intracellular ROS generated by the UVA-irradiated $\mathrm{TiO}_{2}$ coatings and due to UVA irradiation only was estimated with 2,7-dichlorofluorescein diacetate (DCFH-DA). Intracellular ROS convert the nonfluorescent DCFH-DA to fluorescent 2,7-dichlorofluorescein, which is monitored. A stock solution of DCFH-DA (10 mM in methanol) was prepared and kept at $-80^{\circ} \mathrm{C}$ in the dark. Before illumination, bacteria $\left(2.5 \times 10^{6} \mathrm{CFU} \mathrm{ml}-1\right)$ were centrifuged $\left(2500 \mathrm{~g}\right.$ for $5 \mathrm{~min}$ at $\left.4^{\circ} \mathrm{C}\right)$ and the pellets resuspended in $2 \mathrm{ml}$ PBS. An aliquot of DCFH-DA stock solution was added to the bacterial suspension and incubated at $37^{\circ} \mathrm{C}$ for $1 \mathrm{~h}$ under agitation. The solution was then centrifuged ( $2500 \mathrm{~g}$ for $5 \mathrm{~min}$ at $4^{\circ} \mathrm{C}$ ), the supernatant was discarded, and the bacteria resuspended in $1 \mathrm{ml}$ ultrapure sterile water. After exposure to UVA or photocatalysis, the bacterial suspension was collected and centrifuged, the supernatant discarded, and the cells resuspended in $500 \mu$ l of alkaline solution $(0.2$ $\mathrm{M} \mathrm{NaOH}$ containing $1 \%$ SDS) and $1 \mathrm{ml}$ Tris- $\mathrm{HCl}, 40 \mathrm{mM}, \mathrm{pH}$ 7.4. Fluorescence intensity was monitored at excitation $488 \mathrm{~nm} / \mathrm{emission} 525 \mathrm{~nm}$ after 15 minutes. A calibration curve was constructed using fluorescent 2,7-dichlorofluorescein (DCF) to measure the unknown fluorescence signal and relate this to the final concentration of oxidized probe.

\section{Estimation of parameters of inactivation kinetics using a series-event model}

In this model an 'event' is a 'quantum of damage' inflicted on a bacterial cell. The inactivation of a bacterial cell can be viewed as undergoing a series of damaging reactions or events. Damage is considered to occur in integer steps. A certain 
210 number of such events, occurring in series and with kinetics modelled as first order

211 with respect to the cell state, needs to be accumulated by the cell for death to ensue.

212 A series-event model with the following form of model equation (Severin et al., 1983)

213 was used to fit the photocatalytic and UVA inactivation data:

214

215

$$
\frac{C}{C_{o}}=\exp (-k t) \sum_{i=0}^{n-1} \frac{(k t)^{i}}{i !} \quad[\text { eq. 1] }
$$

216 where the magnitude of the inactivation rate constant $k\left(\mathrm{~h}^{-1}\right)$ is dependent on the

217 UVA irradiance, and $C_{0}$ and $C$ are the concentrations of viable bacteria $(\mathrm{CFU} / \mathrm{ml})$ at 218 time zero prior to exposure to UVA and after time $t$ following the start of exposure to 219 UVA or photocatalytically-induced stress. The series-event model has two fitting 220 parameters (rate constant $k$, and the number of damaging events $n$ ), which were 221 numerically varied to achieve a nonlinear least-squares regression fit (using the 222 Levenberg-Marquardt method) to a given set of experimental data (using Datafit 223 software version 9.1.32, Oakdale Engineering, USA).

\section{Statistical analysis}

225 Statistical analysis was carried out using Minitab version 18 (USA). Two-sample t-tests 226 were performed $(n=3)$ with reporting of $p<0.05$ as statistically significant. Error bars 227 represent a single standard deviation, number of replicates indicated in the Figure 228 captions. 


\section{$230 \quad$ Results}

\section{Physical characterization of the coated glass slides}

232 The surface morphology of the coatings was visualized using SEM (Fig. 2). The

$233 \mathrm{TiO}_{2}$-coated glass slides showed no significant changes in morphology between the

234 starting P25 material suspended in ethanol and the deposited $\mathrm{TiO}_{2}$ (data not shown).

235 The size of agglomerates on the slide surface is $\sim 200 \mathrm{~nm}$ (Fig. 2). The thickness of

236 the coatings was typically $\sim 3 \mu \mathrm{m}$ (Fig 2 ). The $\mathrm{TiO}_{2}$ surface coverage indicated a

237 relatively even distribution of the nanoparticles, although there were bare patches on

238 the glass surface (Fig. 2). Typically, the number of dipping cycles needed to achieve

$2390.5 \mathrm{mg}$ of $\mathrm{TiO}_{2}$ deposited per slide was between 8 and 10, giving a coating surface

240 density of $0.02 \mathrm{mg} \mathrm{cm}^{-2}$. Increasing this number did not greatly change the amount of

241 the catalyst deposited on the surface. Complete surface coverage of the catalyst on

242 the glass slide was difficult to achieve without dramatically increasing the number of

243 coating cycles, which was considered unnecessary given that the length scale of the

244 randomly distributed uncoated glass areas was smaller than the size of a typical

245 bacterium. Hence, any bacteria adherent to the glass surface would nevertheless be

246 in at least partial contact with $\mathrm{TiO}_{2}$ nanoparticles.

\section{Photocatalytic activity of the coatings immersed in solution}

248 TPA was always present in excess (hence zero-order concentration dependence) in

249 comparison with the hydroxyl radicals produced during the photocatalytic process.

250 Hence, the production rate of hydroxyl radicals in solution can be calculated from the 251 gradient of the measured concentration of fluorescent hTPA produced during 252 photocatalysis. Hydroxyl radical production at both $\mathrm{LI}$ and $\mathrm{HI}$ was found to be linear 253 (Fig. 3a). At LI the average rate of hydroxyl radical production was $0.32 \mu \mathrm{M} \mathrm{h}^{-1}(95 \%$

$254 \mathrm{Cl}$ range $\left.0.31-0.33 \mu \mathrm{M} \mathrm{h}^{-1}\right)$ and at $\mathrm{HI}$ it was $1.09 \mu \mathrm{M} \mathrm{h}^{-1}(95 \% \mathrm{Cl}$ range $0.77-1.41$ 
$\left.255 \mu \mathrm{M} \mathrm{h}^{-1}\right)$. Hence the rate of hydroxyl radical production is, within experimental

256 uncertainty, proportional to the UVA irradiance at the surface of the coatings.

257 Controls (UVA irradiation in the absence of a $\mathrm{TiO}_{2}$ coating) yielded no production of 258 hydroxyl radicals (data not shown).

259 Assessment of the effect of irradiance on the photocatalytic degradation of ITS in the 260 presence of the coated substrates was carried out as an indicator of the overall rate 261 of ROS production (Fig. 3b). 95\% of ITS was degraded in $7 \mathrm{~h}$ at $\mathrm{LI}$ and in $4 \mathrm{~h}$ at $\mathrm{HI}$.

262 ITS degradation was found to follow first order kinetics and an exponential 263 regression model (of the form $a e^{-b t}$ ) was therefore appropriate. Fitted parameters: for $\mathrm{LI}, a=58.6 \mu \mathrm{M}, 95 \% \mathrm{Cl}(54-62.6) ; b=0.35 \mathrm{~h}^{-1}, 95 \% \mathrm{Cl}(0.38-0.30)$ and for $\mathrm{HI}, a=$ $59.9 \mu \mathrm{M}, 95 \% \mathrm{Cl}(48.3-71.4) ; b=0.61 \mathrm{~h}^{-1}, 95 \% \mathrm{Cl}(0.83-0.40)$. Initial degradation rates (at $t=0$ ) were $20.5 \mu \mathrm{M} \mathrm{h}^{-1}$ for $\mathrm{LI}$ and $36.5 \mu \mathrm{M} \mathrm{h}^{-1}$ for HI. The controls (UVA

267 irradiation in the absence of a $\mathrm{TiO}_{2}$ coating) showed a modest decrease in ITS 268 concentration (Fig. 3), which was fitted with a linear regression model yielding rates of $1.5 \mu \mathrm{M} \mathrm{h}^{-1}$ for LI and $5.8 \mu \mathrm{M} \mathrm{h}^{-1}$ for $\mathrm{HI}$. Unlike hydroxyl radical production, there was no evidence that ex vivo ROS production is proportional to irradiance; it was

271 markedly subproportional.

272 Photocatalytic inactivation of S. aureus (wild type and mutants) and 273 intracellular oxidative stress

274 Inactivation kinetics and intracellular oxidative stress for wild type

275 At LI over $8 \mathrm{~h}$ the viable cell concentration for the WT strain was stable for both UVA276 only exposed controls (without coatings) and samples exposed to UVA in the 277 presence of $\mathrm{TiO}_{2}$ coatings, producing ROS (Fig. 4a). 4 h of HI UVA exposure was 278 needed for a $\sim 1$ log reduction in viable cell concentration; it was not possible to 
279 discriminate between the level of killing achieved using HI UVA alone and samples 280 exposed to $\mathrm{HI}$ UVA in the presence of $\mathrm{TiO}_{2}$ coatings (Fig. 4a). LI UVA exposure for $2818 \mathrm{~h}$ resulted in low intracellular DCF concentrations $(<0.2 \mathrm{mM})$ in the WT strain (Fig. 282 5a). There was a statistically significant difference $(P<0.05)$ in intracellular ROS 283 levels in bacteria exposed to UVA only and those exposed to UVA in the presence of 284 the $\mathrm{TiO}_{2}$ coatings. This suggests a measurable effect of photocatalytically induced 285 ROS on intracellular oxidative stress levels.

286 No viable S. aureus wild type cells were detected in solution upon exposure to LI 287 UVA in the presence of coatings after $24 \mathrm{~h}$ (Fig. 6a). Exposure for $6 \mathrm{~h}$ at HI UVA (i.e. 288 replicating the $24 \mathrm{~h} \mathrm{LI}$ dose-irradiance multiplied by exposure time) resulted in a 289 considerable decrease ( 2 log) in viable cell concentration. No significant difference 290 in viable bacterial counts was observed between the HI UVA-treated and the $\mathrm{TiO}_{2}-$ 291 coated samples (Fig. 6a). A significant increase in intracellular DCF concentration 292 ( 2 mM) was measured for the WT strain in the presence of $\mathrm{TiO}_{2}$ coatings exposed 293 to $24 \mathrm{~h} \mathrm{LI} \mathrm{UVA} \mathrm{(Fig.} \mathrm{6b).} \mathrm{Intracellular} \mathrm{DCF} \mathrm{concentration} \mathrm{for} \mathrm{the} \mathrm{control} \mathrm{sample} \mathrm{(WT}$ 294 strain exposed to LI UVA for $24 \mathrm{~h}$ without $\mathrm{TiO}_{2}$ coatings) was significantly lower $\sim 0.5$ $295 \mathrm{mM}$ (Fig. 6b). These results suggest a significant increase in intracellular oxidative 296 stress following $24 \mathrm{~h} \mathrm{LI} \mathrm{UVA} \mathrm{exposure} \mathrm{in} \mathrm{the} \mathrm{presence} \mathrm{of} \mathrm{TiO}_{2}$ coatings, which 297 correlates with the killing of the WT strain.

298 Inactivation kinetics and intracellular oxidative stress for the ahpC/katA catalase299 negative mutant

300 The ahpC/katA mutant strain showed 1.5 log greater inactivation for bacterial 301 samples exposed to LI UVA for $8 \mathrm{~h}$ in the presence of $\mathrm{TiO}_{2}$ coatings compared with 302 UVA controls (Fig. 4b). The inactivation kinetic data was fitted with a series-event 
model. The optimum fitted value of the threshold number of events was $n=10$ and the

304 fitted inactivation rate constant for the coated samples was $k=2.30 \mathrm{~h}^{-1}$ and for the

UVA controls $1.75 \mathrm{~h}^{-1}$, indicating faster inactivation in the presence of the coating, presumably due to the production of ROS (Table S1). A 3 log reduction in viable cell concentration took $4 \mathrm{~h}$ upon exposure of the ahpC/katA mutant strain to HI UVA and it was not possible to discern differences in lethality between UVA controls (no coating) and the $\mathrm{TiO}_{2}$-coated samples at any time point, suggesting no additional effect of $\mathrm{TiO}_{2}$-induced ROS in comparison with $\mathrm{HI}$ UVA alone (Fig. 4b). The inactivation kinetics data was fitted by a series-event model with $n=10$. The

312 inactivation rate constant for the coated samples was found to be $4.65 \mathrm{~h}^{-1}$ and for the 313 UVA controls $4.56 \mathrm{~h}^{-1}$, indicating faster inactivation at $\mathrm{HI}$ compared with $\mathrm{LI}$, but the 314 rate constant for $\mathrm{HI}\left(4 \mathrm{~mW} / \mathrm{cm}^{2}\right)$ was not found to be four times that for $1 \mathrm{~mW} / \mathrm{cm}^{2}$ 315 (LI). Less than 1 log reduction was observed after $2 \mathrm{~h} \mathrm{HI}$ exposure compared with a $3163 \log$ reduction at $\mathrm{LI}$ for the same overall dose for samples in the presence of $\mathrm{TiO}_{2}$ 317 coatings (Fig. 4b). A considerably greater degree of lethality was therefore achieved 318 with LI UVA compared with $\mathrm{HI}$ for the same radiation exposure dose in the presence 319 of the photocatalytic coatings. This indicates bacteria were more susceptible to LI UVA killing compared with $\mathrm{HI}$ for the same total radiation dose and suggests that the 321 bacteria activate a defence mechanism in response to HI UVA, a mechanism that is 322 not activated during LI UVA exposure.

323 Intracellular DCF concentration $(\sim 0.3 \mathrm{mM})$ for the ahpC/katA strain exposed to $\mathrm{TiO}_{2}$ 324 was significantly higher compared with the UVA-only controls at LI (Fig. 5a). This 325 suggests photocatalytically induced intracellular oxidative stress due to ROS 326 production by $\mathrm{TiO}_{2}$. Irradiance of the bacteria at $\mathrm{HI}$ for $2 \mathrm{~h}$ resulted in a significant increase in intracellular DCF concentrations $(\sim 1 \mathrm{mM})$ in the ahpC/katA mutant strain 
328 for both UVA controls and $\mathrm{TiO}_{2}$-coated samples and no significant difference 329 between them (Fig. 5b).

330 Inactivation kinetics and intracellular oxidative stress for the sodA/sodM mutant

331 The sodA/sodM mutant strain was highly sensitive to LI ROS production by $\mathrm{TiO}_{2}$

332 showing a $\sim 5$ log decrease in viability in the presence of the $\mathrm{TiO}_{2}$ coating. In the 333 absence of the photocatalytic coating there was no bactericidal effect (Fig. 4c). The 334 inactivation kinetics fitted with a series-event model $(n=10)$ yielded an inactivation 335 rate constant of $2.57 \mathrm{~h}^{-1}$ for the coated samples, indicating faster inactivation 336 compared with the catalase mutant strain. $4 \mathrm{~h} \mathrm{HI}$ exposure resulted in a $\sim 3 \mathrm{log}$ 337 decrease in viable cells and no discernible differences between the viable cell 338 concentrations for UVA controls and $\mathrm{TiO}_{2}$-coated samples at any time (Fig. 4c). This suggests no additional effect of photocatalytic ROS in comparison with HI UVA

340 alone. The inactivation kinetic data did not fit the series-event model (typical of 341 concave inactivation curves with a shoulder) when $n=10$ was used for fitting the 342 data, but did fit with $n=1$. The inactivation rate constant for the coated samples was $3431.31 \mathrm{~h}^{-1}$ and for the UVA controls $1.28 \mathrm{~h}^{-1}$. Less than 2 log decrease in viable cells 344 was observed after $2 \mathrm{~h}$ exposure to $\mathrm{HI}$ UVA in the presence of $\mathrm{TiO}_{2}$ coatings 345 compared with 5 log reduction at LI for the same dose.

346 Intracellular DCF concentration for 8h LI UVA exposure in the presence of $\mathrm{TiO}_{2}$

347 coatings for the sodA/sodM strain had the highest value ( $0.5 \mathrm{mM}$, Fig. $5 \mathrm{a})$

348 compared with the WT and ahpC/katA strains. This suggests significant 349 photocatalytically induced intracellular oxidative stress due to ROS production by $350 \mathrm{TiO}_{2}$. Irradiance of the sodA/sodM mutants at $\mathrm{HI}$ for $2 \mathrm{~h}$ resulted in a significant 
351 increase in intracellular DCF concentrations $(\sim 1 \mathrm{mM})$ for both UVA controls and

$352 \mathrm{TiO}_{2}$-coated samples with no significant difference between them (Fig. 5b).

\section{Discussion}

354 The main product of oxygen reduction by $\mathrm{TiO}_{2}$ photocatalysis is superoxide $\cdot \mathrm{O}_{2}{ }^{-}$, which can pick up a proton to form the perhydroxyl radical $\bullet \mathrm{OOH}$ (Ramsden, 2015). Meanwhile hydroxyl ions are oxidized to hydroxyl radicals $\cdot \mathrm{OH}$ (Ramsden, 2015). Elevation in the intracellular levels of these oxidants, notably superoxide ${ }^{\circ} \mathrm{O}_{2}{ }^{-}$, results in enzyme damage and may accelerate mutagenesis (Imlay, 2015). In contrast to some other common bacteria like E. coli, S. aureus synthesizes only one catalase protein but also uses AhpC alkylhydroperoxide reductase to degrade peroxide (Antelmann et al., 1996; Horsburgh et al., 2001; Loewen, 1984). Catalase is well known for its ability to detoxify intracellular hydrogen peroxide (Mandell, 1975; Pezzoni et al., 2016). However, the most important role of catalase is to avoid formation of hydroxyl radicals through the Fenton reaction between $\mathrm{H}_{2} \mathrm{O}_{2}$ and iron in the cell (Cosgrove et al., 2007). S. aureus has two SODencoding genes, sodA and sodM. The products of translation of mRNA are two homodimers and a heterodimer that combine to give rise to three activity centres for SOD

367 (Clements et al., 1999; Valderas and Hart, 2001). SOD is a metalloprotein that converts $368 \mathrm{O}_{2}^{-}$to $\mathrm{H}_{2} \mathrm{O}_{2}$ and $\mathrm{O}_{2}$, preventing not only direct damage caused by $\mathrm{O}_{2}^{-}$but also the toxicity 369 of the $\mathrm{Fe}^{3+}$-dependent catalytic reactions leading to $\mathrm{OH}$ via the Haber-Weiss reaction 370 (Haber and Weiss, 1934). In the WT strain intracellular ROS concentrations are held in 371 check by the superoxide dismutases that degrade $\cdot \mathrm{O}_{2}{ }^{-}$and the peroxidases and catalases

372 that degrade $\mathrm{H}_{2} \mathrm{O}_{2}$. Mutants that lack either set of enzymes suffer damage to specific 373 enzymes and are unable to grow under conditions requiring their activity (Gu and Imlay, 374 2013). 
$376 \mathrm{TiO}_{2}$-coated glass substrates immersed in water and exposed to LI UVA-generated ROS

377 in the water (Fig. 3). It was possible to discriminate between the bactericidal effect of LI

378 UVA alone and that due to ROS production by the $\mathrm{TiO}_{2}$ coatings. The $\operatorname{sod} A /$ sodM and to a 379 lesser extent the ahpC/katA mutant strains were found to be resistant to LI UVA damage 380 but were highly susceptible to $\mathrm{TiO}_{2}$-induced $\mathrm{ROS}$ over the same exposure period. The WT 381 strain was considerably more resistant; nevertheless, after $24 \mathrm{~h} \mathrm{LI}$ exposure no viable 382 cells were culturable. Measurement of intracellular DCF formation showed differential 383 levels of intracellular oxidative stress at LI, with the highest measured levels in the $384 \operatorname{sod} A /$ sodM mutant strain followed by the ahpC/katA mutant strain and considerably lower 385 levels in the WT strain (Fig. 5a). Intracellular levels of DCF for LI UVA-only exposed samples were significantly less in comparison with the $\mathrm{TiO}_{2}$-exposed samples (Fig. 5a). Intracellular levels of DCF increased in the WT strain after LI exposure for $24 \mathrm{~h}$ and were much higher in comparison with WT exposed to LI UVA only (Fig. 6b). Inactivation kinetics and the intracellular oxidative stress data suggest that superoxide dismutases that degrade $\cdot \mathrm{O}_{2}^{-}$play a significant role in affording protection against ROS under LI UVA. Hydrogen peroxide levels in solution were below the limit of detection $(<0.1 \mathrm{mM}$ and below the minimum inhibitory concentration $>10 \mathrm{mM}$ ) even after $24 \mathrm{~h}$ irradiation with UV in the presence of the $\mathrm{TiO}_{2}$ coatings. Previous studies with NUV corroborate these results; researchers did not find elevated levels $(>1 \mu \mathrm{M})$ of hydrogen peroxide at similar low fluence rates (Kramer and Ames, 1987). This does not rule out the involvement of low levels of hydrogen peroxide in the formation of more toxic oxygen species (Pezzoni et al., 2016). Addition of sublethal amounts of hydrogen peroxide during NUV irradiation was found to increase bacterial cell death rates and thought to result from superoxide anion 399 formation which may react further with hydrogen peroxide to yield reactive hydroxyl 
400 radicals measured here (Liochev and Fridovich, 2010). Bulk $\bullet \mathrm{OH}$ radical generation rate 401 was directly related to the level of light irradiance (Fig. 3) and was likely formed by the 402 well-known Haber-Weiss reaction in which $\mathrm{H}_{2} \mathrm{O}_{2}$ reacts with $\cdot \mathrm{O}_{2}^{-}$to give bulk $\cdot \mathrm{OH}$ directly 403 in solution (Hirakawa and Nosaka, 2002).

404

405 Decoupling the effect of intracellular ROS-induced stress at $\mathrm{HI}$ UVA due to $\mathrm{TiO}_{2}$ 406 photocatalysis compared with that caused by HI UVA alone was not possible (Figs. 4 and 407 5). Comparison of $\mathrm{HI}$ inactivation kinetics for the ahpC/katA and sodA/sodM mutants 408 suggested that intracellular superoxide $\cdot \mathrm{O}_{2}^{-}$formation caused rapid killing of the SOD 409 mutant while the catalase mutant initially showed resistance to HI UVA damage 410 (characteristic shoulder seen on the inactivation curve) but irradiation continuing after 411 about 90 min of initial exposure to HI UVA resulted in cells beginning to rapidly die (the decay rate was faster during this interval in comparison with that of the SOD). The WT

413 strain exposed to HI UVA started showing some viability loss after 4 h of exposure (Fig. 414 4a) increasing to over 2 log reduction after $6 \mathrm{~h}$ (Fig. 6a). In the WT strain, intracellular 415 enzymes presumably afford initial protection to UVA-induced ROS damage; however, accumulating levels of ROS have been shown to damage intracellular enzymes making

417 the cells susceptible to oxidative damage if exposure continues (Imlay, 2015).

419 Bacteria are known to be resistant to short exposures of the near-UV (NUV) component of 420 the solar spectrum $(\lambda=300-400 \mathrm{~nm})$ at irradiances mimicking natural sunlight $(3.5-5$ $421 \mathrm{~mW} / \mathrm{cm}^{2}$ corresponding to $\mathrm{HI}$ ) but begin to die rapidly after 3 to $4 \mathrm{~h}$ of exposure (Kramer 422 and Ames, 1987). Exposure to HI UVA may involve photosensitization by endogenous 423 NUV-absorbing chromophores resulting in their excitation followed by reaction with 424 dissolved intracellular $\mathrm{O}_{2}$ resulting in intracellular ROS production (Fig. 5b) and oxidative 
425 damage (Kramer and Ames, 1987). Involvement of the oxidative defense regulon oxyR in

426 affording protection to intracellular oxidative stress has previously been shown to be

427 crucial in protecting bacteria against NUV damage (Eisenstark, 1998; Wei et al., 2012).

428 UVA-induced oxidative damage and, ultimately, cytotoxicity has been shown to be dependent on radiation intensity not just the total energy dose (Eisenstark, 1987). UVA radiation generates active oxygen species, including hydrogen peroxide, inside 431 irradiated bacteria (Cunningham et al., 1985; Czochralska et al., 1984; McCormick et 432 al., 1976; Pezzoni et al., 2016). Intracellular oxidative stress at LI and HI (using the same total energy dose) were measured using the DCFH probe (Fig. 5). In the absence of the titania coatings, very low intracellular concentration of fluorescent DCF was detected at LI, indicating low intracellular ROS production (Fig. 5a).

436 Exposed for the same dose of UVA only but using $\mathrm{HI}$, the intracellular concentration 437 of fluorescent DCF increased dramatically (Fig. 5b). It is unclear whether UVA has contributed to the increase in intracellular ROS directly; e.g., through the tryptophan and/or NADP/NADPH pathway, or indirectly through inactivating the bacterial enzymes for disarming ROS. Regulatory gene products are known to be triggered

441 upon excess NUV oxidation leading to synthesis of entire batteries of anti-oxidant 442 enzymes, DNA repair enzymes etc., which may explain the results reported here 443 (Eisenstark, 1998; Pezzoni et al., 2016; Sassoubre et al., 2014).

445 Inactivation results at the same 'inactivation dose' for the WT strain at LI (24 h 446 exposure) and $\mathrm{HI}$ (6 h exposure) did not follow the Bunsen-Roscoe reciprocity law 447 applicable to simple photochemical processes. This law states that the effect of 448 radiation depends on the total radiant energy received and is independent of 449 irradiance and duration. In the case of S. aureus WT strain the photochemical effect 
450 was found not to follow the reciprocity law. At high irradiance the presence of the

451 titania had no additional effect on bacterial viability compared with UVA alone, and

452 the degree of intracellular oxidative stress was the same regardless of the presence

453 or absence of catalase/AhpC or SOD. On the other hand, at low irradiance, survival

454 of the mutants lacking catalase/AhpC or SOD was severely compromised by the

455 presence of titania, and all bacterial forms, even the wild-type, had significantly

456 increased internal oxidative stress compared with UVA alone. For the WT strain,

457 after $24 \mathrm{~h}$ of exposure at low irradiance $\left(1 \mathrm{~mW} / \mathrm{cm}^{2}-\mathrm{cf}\right.$. ordinary interior lighting,

458 which is typically around $0.1 \mathrm{~mW} / \mathrm{cm}^{2}$ ) all the bacteria were killed in the presence of

459 the titania coatings ( 7 log reduction), whereas when the same exposure was

460 delivered at $4 \mathrm{~mW} / \mathrm{cm}^{2}$, about $1 \%$ of the bacteria survived (2 log reduction),

461 regardless of the presence of titania; a similar proportion survived at $1 \mathrm{~mW} / \mathrm{cm}^{2}$ (after

$46224 \mathrm{~h}$ exposure) in the absence of titania (Fig. 6a). This implies that when the

463 irradiance exceeds a threshold (corresponding to a level somewhere between LI and

$464 \mathrm{HI}$ ), certain defence mechanisms are activated, which affords protection to the

465 bacterium from the ROS generated both by UVA and by the titania coating. LI, which

466 still greatly exceeds typical interior irradiance, failed to activate these defence

467 mechanisms and in consequence the WT strain accumulated damage and was

468 effectively inactivated in the presence of titania after $24 \mathrm{~h}$ exposure. A previous study

469 with E. coli irradiated with UVA at $365 \mathrm{~nm}$ reported a similar result; $E$. coli cells were

470 found to be more resistant at high irradiance in comparison with low irradiance with

471 reciprocity found only at high values above $75 \mathrm{~mW} / \mathrm{cm}^{2}$; considerably higher than

472 those used in the present study (Peak and Peak, 1982). These observations are

473 supported by another study using E. coli cells and UVA which showed that

474 increasing the light intensity from $0.48 \mathrm{~mW} / \mathrm{cm}^{2}$ to $3.85 \mathrm{~mW} / \mathrm{cm}^{2}$ i.e. an 8 -fold 
475 increase, resulted in only halving of the bacteria killing time from $180 \mathrm{~min}$ to $90 \mathrm{~min}$

476 respectively (Benabbou et al., 2007).

\section{Conclusions}

478 LI UVA in the presence of surface-immobilized $\mathrm{TiO}_{2}$ was shown to result in the production 479 of ROS in solution and increased intracellular levels of oxidative stress, which over $24 \mathrm{~h}$ 480 was found to be lethal for the WT S. aureus strain. These results are encouraging for the 481 deployment of antibacterial titania surface coatings; e.g., for hospital interiors such as 482 wards and surgical theatres as well as in vehicles, hotels and restaurants—wherever it is 483 desirable to reduce the environmental bacterial burden; the titania may be thought to 484 operate by a "stealth" mechanism, generating lethal ROS against which the wild type bacteria are defenceless because at these low light levels the oxidative stress defence mechanisms are not triggered. The LI irradiance used in the present study was an order of magnitude higher than typical indoor irradiance; future studies should investigate whether there is a low irradiance threshold correlating with a minimum photocatalytic induced ROS dose which is needed for inactivation of $S$. aureus. We have, moreover, shown the level of photocatalytic activity and timescales needed to inactivate $S$. aureus. The methods used

491 to evaluate the coatings may help in evaluating the performance of commercial

492 photocatalytic coatings designed to be used in practical indoor settings.

\section{Acknowledgements}

494 The authors would like to acknowledge EPSRC support for this work (Grant no. 495 EP/M027341/1, Tackling Antimicrobial Resistance: An Interdisciplinary Approach), 496 and support from the Collegium Basilea (Institute for Advanced Study), Basel, 497 Switzerland. 


\section{Conflict of Interest}

500 No conflict of interest is declared.

\section{References}

502 Antelmann, H., Engelmann, S., Schmid, R., and Hecker, M. (1996). General and 503 oxidative stress responses in Bacillus subtilis : cloning, expression, and 504 mutation of the alkyl hydroperoxide reductase operon. J. Bacteriol. 178, 6571$505 \quad 6578$.

506 Benabbou, A. K., Derriche, Z., Felix, C., Lejeune, P., and Guillard, C. (2007).

507 Photocatalytic inactivation of Escherischia coli Effect of concentration of $\mathrm{TiO}_{2}$ 508 and microorganism, nature, and intensity of UV irradiation. Appl. Catal. B $509 \quad$ Environ. 76, 257-263. doi:10.1016/j.apcatb.2007.05.026.

510 Clements, M. O., Watson, S. P., and Foster, S. J. (1999). Characterization of the 511 major superoxide dismutase of Staphylococcus aureus and its role in starvation 512 survival, stress resistance, and pathogenicity. J. Bacteriol. 181, 3898-3903.

513 Cosgrove, K., Coutts, G., Jonsson, I.-M., Tarkowski, A., Kokai-Kun, J. F., Mond, J. 514 J., et al. (2007). Catalase (KatA) and alkyl hydroperoxide reductase (AhpC) have compensatory roles in peroxide stress resistance and are required for survival, persistence, and nasal colonization in Staphylococcus aureus. J. Bacteriol. 189, 1025-1035. doi:10.1128/JB.01524-06.

518 Cunningham, M. L., Johnson, J. S., Giovanazzi, S. M., and Peak, M. J. (1985). PHOTOSENSITIZED PRODUCTION OF SUPEROXIDE ANION BY MONOCHROMATIC (290-405 nm) ULTRAVIOLET IRRADIATION OF NADH and NADPH COENZYMES. Photochem. Photobiol. 42, 125-128. 
523 Czochralska, B., Kawczynski, W., Bartosz, G., and Shugar, D. (1984). Oxidation of 524 excited-state NADH and NAD dimer in aqueous medium involvement of O2-as a 525 mediator in the presence of oxygen. Bochimica Biophys. Acta 801, 403-409. doi:10.1016/0304-4165(84)90145-4.

527 Dancer, S. J. (2008). Importance of the environment in meticillin-resistant 528 Staphylococcus aureus acquisition: the case for hospital cleaning. Lancet Infect. 529 Dis. 8, 101-13. doi:10.1016/S1473-3099(07)70241-4.

Dorta-Schaeppi, Y., and Treadwell, W. D. (1949). Ueber eine kolorimetrische Bestimmung von hochverdiinntem Ozon in Sauerstoff. Heir. chim. Acta 32, 356364.

533 Eisenstark, A. (1987). Mutagenic and lethal effects of near-ultraviolet radiation (290$400 \mathrm{~nm}$ ) on bacteria and phage. Environ. Mol. Mutagen. 10, 317-337. doi:10.1002/em.2850100311.

536 Eisenstark, A. (1998). Bacterial gene products in response to near-ultraviolet radiation. Mutat. Res. - Fundam. Mol. Mech. Mutagen. 422, 85-95. doi:10.1016/S0027-5107(98)00178-X.

539 Goodman, E. R., Platt, R., Bass, R., Onderdonk, A. B., Yokoe, D. S., and Huang, S. 540 S. (2008). Impact of an environmental cleaning intervention on the presence of 541 methicillin-resistant Staphylococcus aureus and vancomycin-resistant 542 enterococci on surfaces in intensive care unit rooms. Infect. Control Hosp. $543 \quad$ Epidemiol. 29, 593-9. doi:10.1086/588566.

544 Gu, M., and Imlay, J. A. (2013). Superoxide poisons mononuclear iron enzymes by 

causing mismetallation. Mol. Microbiol. 89, 123-134. doi:10.1111/mmi.12263.

546 Haber, F., and Weiss, J. (1934). The catalytic decomposition of hydrogen peroxide 547 by iron salts. Proc. R. Soc. A Math. Phys. Eng. Sci. 147, 332-351.

548 Hardy, K. J., Gossain, S., Henderson, N., Drugan, C., Oppenheim, B. a, Gao, F., et al. (2007). Rapid recontamination with MRSA of the environment of an intensive care unit after decontamination with hydrogen peroxide vapour. J. Hosp. Infect. 66, 360-8. doi:10.1016/j.jhin.2007.05.009.

Hirakawa, T., and Nosaka, Y. (2002). Properties of O2.- and OH. Formed in TiO2 aqueous suspensions by photocatalytic reaction and the influence of $\mathrm{H} 2 \mathrm{O} 2$ and some ions. Langmuir 18, 3247-3254. doi:10.1021/la015685a.

Horsburgh, M. J., Clements, M. O., Crossley, H., Ingham, E., and Foster, S. J. (2001). PerR controls oxidative stress resistance and iron storage proteins and is required for virulence in Staphylococcus aureus. Infect. Immun. 69, 37443754. doi:10.1128/IAI.69.6.3744.

Imlay, J. A. (2015). Diagnosing oxidative stress in bacteria: not as easy as you might think. Curr. Opin. Microbiol. 24, 124-131. doi:10.1016/j.mib.2015.01.004.

Karavolos, M. H., Horsburgh, M. J., Ingham, E., and Foster, S. J. (2003). Role and 562 regulation of the superoxide dismutases of Staphylococcus aureus. Microbiology 149, 2749-2758. doi:10.1099/mic.0.26353-0.

564 Khan, a S., Dancer, S. J., and Humphreys, H. (2012). Priorities in the prevention 565 and control of multidrug-resistant Enterobacteriaceae in hospitals. J. Hosp. $566 \quad$ Infect. 82, 85-93. doi:10.1016/j.jhin.2012.06.013. 
567 Kikuchi, Y., Sunada, K., Iyoda, T., Hashimoto, K., and Fujishima, A. (1997).

568 Photocatalytic bactericidal effect of TiO2 thin films: dynamic view of the active oxygen species responsible for the effect. J. Photochem. Photobiol. A Chem.

570 106, 51-56. doi:10.1016/S1010-6030(97)00038-5.

571 Kramer, A., Schwebke, I., and Kampf, G. (2006). How long do nosocomial

572 pathogens persist on inanimate surfaces? A systematic review. BMC Infect. Dis.

$573 \quad 6,130$. doi:10.1186/1471-2334-6-130.

574 Kramer, G. F., and Ames, B. N. (1987). Oxidative Mechanisms of Toxicity of Low575 Intensity Near-UV Light is Salmonella typhimurium. J. Bacteriol. 169, 22595762266.

577 Kühn, K. P., Chaberny, I. F., Massholder, K., Stickler, M., Benz, V. W., Sonntag, H. $578 \quad$ G., et al. (2003). Disinfection of surfaces by photocatalytic oxidation with 579 titanium dioxide and UVA light. Chemosphere 53, 71-77. doi:10.1016/S0045$580 \quad 6535(03) 00362-X$

581 Liochev, S. I., and Fridovich, I. (2010). Mechanism of the peroxidase activity of Cu, 582 Zn superoxide dismutase. Free Radic. Biol. Med. 48, 1565-1569.

583 doi:10.1016/j.freeradbiomed.2010.02.036.

584 Loewen, P. C. (1984). Isolation of catalase-deficient Escherichia coli mutants and 585 genetic mapping of katE. a locus that affects catalase activity. J. Bacteriol. 157, 586 $622-626$.

587 Machala, Z., Tarabova, B., Hensel, K., Spetlikova, E., Sikurova, L., and Lukes, P. 588 (2013). Formation of ROS and RNS in water electro-sprayed through transient 589 spark discharge in air and their bactericidal effects. Plasma Process. Polym. 10, 

649-659. doi:10.1002/ppap.201200113.

591 Mandell, G. L. (1975). Catalase, superoxide dismutase, and virulence of 592 Staphylococcus aureus. In vitro and in vivo studies with emphasis on 593 staphylococcal--leukocyte interaction. J. Clin. Invest. 55, 561-566.

594 doi:10.1172/JCl107963.

595

596

597

598

599

600

601

602

603

604

605

606

607

608

609

610

Mason, T. J., Lorimer, J. P., Bates, D. M., and Zhao, Y. (1994). Dosimetry in sonochemistry: the use of aqueous terephthalate ion as a fluorescence monitor. Ultrason. - Sonochemistry 1, S91-S95. doi:10.1016/1350-4177(94)90004-3.

Matsunaga, T., Tomoda, R., Nakajima, T., and Wake, H. (1985). Photochemical sterilization of microbial cells by semiconductor powders. FEMS Microbiol. Lett. $29,211-214$.

McCormick, J., Fischer, J., Pachlatko, J., and Eisenstark, A. (1976). Characterization of a Cell-Lethal Product from the Photooxidation of Tryptophan: Hydrogen Peroxide. Science (80-. ). 191, 468-469.

Merwald, H., Klosner, G., Kokesch, C., Der-Petrossian, M., Hönigsmann, H., and Trautinger, F. (2005). UVA-induced oxidative damage and cytotoxicity depend on the mode of exposure. J. Photochem. Photobiol. B Biol. 79, 197-207. doi:10.1016/j.jphotobiol.2005.01.002.

Nakano, R., Hara, M., Ishiguro, H., Yao, Y., Ochiai, T., Nakata, K., et al. (2013). Broad Spectrum Microbicidal Activity of Photocatalysis by TiO2. Catalysts 3, 310-323. doi:10.3390/catal3010310.

611 O’Neill, J. (2016). Tackling Drug-Resistant Infections Globally: Final Report and 612 Recommendations. Rev. Antimicrob. Resist., 84. 

doi:10.1016/j.jpha.2015.11.005.

614 Peak, J. G., and Peak, M. J. (1982). Lethality in repair-proficient Escherichia Coli 615 after $365 \mathrm{~nm}$ ultraviolet light irradiation is dependent on fluence rate. Photochem. Photobiol. 36, 103-105.

617 Pezzoni, M., Tribelli, P. M., Pizarro, R. A., López, N. I., and Costa, C. S. (2016).

618 Exposure to low UVA doses increases KatA and KatB catalase activities, and confers cross-protection against subsequent oxidative injuries in Pseudomonas aeruginosa. Microbiology 162, 855-864. doi:10.1099/mic.0.000268.

621

Ramsden, J. J. (2015). Photocatalytic antimicrobial coatings. Nanotechnol. Perceptions 11, 146-168.

623 Ramsden, J. J. (2017). Can bacteria develop resistance to photocatalytically generated reactive oxygen species? J. Biol. Phys. Chem. 17, 47-51.

625 Rastogi, G. V. K. (2007). Relevant to Medical Treatment Facilities with Ultraviolet C $626 \quad$ Light. Mil. Med. 172, 1166-1169.

627 Reid, M., Whatley, V., Spooner, E., Nevill, A. M., Cooper, M., Ramsden, J. J., et al. 628 (2018). How Does a Photocatalytic Antimicrobial Coating Affect Environmental 629 Bioburden in Hospitals? Infect. Control Hosp. Epidemiol. 39, 398-404. $630 \quad$ doi:10.1017/ice.2017.297.

631 Sassoubre, L. M., Ramsey, M. M., Gilmore, M. S., and Boehm, A. B. (2014). 632 Transcriptional response of Enterococcus faecalis to sunlight. J. Photochem. 633 Photobiol. B Biol. 130, 349-356. doi:10.1016/j.jphotobiol.2013.12.013.

634 Severin, B. F., Suidan, M. T., and Engelbrecht, R. S. (1983). Kinetic modeling of U.V. 
disinfection of water. Water Res. 17, 1669-1678. doi:10.1016/0043-

636 1354(83)90027-1.

637 Sunada, K., Watanabe, T., and Hashimoto, K. (2003). Studies on photokilling of 638 bacteria on TiO2thin film. J. Photochem. Photobiol. A Chem. 156, 227-233. 639 doi:10.1016/S1010-6030(02)00434-3.

640 Valderas, M. W., and Hart, M. E. (2001). Identification and Characterization of a 641 Second Superoxide Dismutase Gene (sodM) from Staphylococcus aureus. J. 642 Bacteriol. 183, 3399-3407. doi:10.1128/JB.183.11.3399.

643 Wei, Q., Le Minh, P. N., Dötsch, A., Hildebrand, F., Panmanee, W., Elfarash, A., et 644 al. (2012). Global regulation of gene expression by OxyR in an important human 645 opportunistic pathogen. Nucleic Acids Res. 40, 4320-4333.

646 doi:10.1093/nar/gks017.

647 White, L. F., Dancer, S. J., Robertson, C., and McDonald, J. (2008). Are hygiene 648 standards useful in assessing infection risk? Am. J. Infect. Control 36, 381-4. 649 doi:10.1016/j.ajic.2007.10.015.

650 Zhang, J., Zhou, P., Liu, J., and Yu, J. (2014). New understanding of the difference 651 of photocatalytic activity among anatase, rutile and brookite TiO2. Phys. Chem. 652 Chem. Phys. 16, 20382-20386. doi:10.1039/c4cp02201g. 